\title{
The debate on child and adolescent psychiatric research is going global
}

\author{
Andre Sourander ${ }^{1,2} \cdot$ Roshan Chudal $^{1}$
}

Published online: 9 April 2017

(C) Springer-Verlag Berlin Heidelberg 2017

Mental disorders are now one of the most common causes of global morbidity and they accounted for $7.4 \%$ of all disability adjusted life years in 2010 [1]. Up to $20 \%$ of children and adolescents across the world suffer from a disabling mental illness in any given year and almost a third will experience a mental disorder at some point during their life [2]. More than half of the mental health disorders in adulthood will have started by the age of 14 years [3] and this early disease onset, together with the chronic course of a poor mental health and the likelihood that the scale of the problem is underestimated, highlights the enormous global burden of child and adolescent mental health (CAMH) problems. This increasing burden has heightened our awareness of the need for responsive services, early identification and effective prevention [4]. However, attempts to improve child and adolescent psychiatry (CAP) have been hampered by limited numbers of medical professionals in countries with existing CAP services and the lack of existing CAP frameworks in other countries.

Most of the existing CAP research has come from the western world and the view for some time has been that these findings are valid for the rest of the world. But extrapolating these results without any comparable regional data is unlikely to present a true global picture of CAP. In more recent years we have seen an increase in the amount of

Andre Sourander

andre.sourander@utu.fi

Roshan Chudal

roshan.chudal@utu.fi

1 Department of Child Psychiatry, University of Turku, Turku, Finland

2 Department of Child Psychiatry, Turku University Hospital, Turku, Finland
CAP research stemming from previously under-researched areas, like Asia, which is a very promising sign. That is why it is so good to see that this issue of the ECAP Journal includes two excellent and methodologically sound research articles from China and Taiwan.

$\mathrm{Wu}$ et al. [5] studied the associations between screen time, sleep duration and behavior problems in preschool children in the Anhui and Jiangsu provinces in east China. Children worldwide are spending an increasing amount of their time exposed to screen-based activities, such as televisions, computers and smart phones. This raises an important public health question about whether increased screen time in early childhood is associated with negative health outcomes and shorter sleep duration. The Chinese study sample was impressive, as it comprised 8900 children aged 3-6 years and one of its strengths was the authors' ability to adjust the findings using a large number of covariates. It found that children with long screen times and short sleep duration were more likely to have behavioural problems, including particularly high scores for autism spectrum disorder. These findings are relevant for future research, as well as for parents, educators and the policy makers, who are responsible for preventing psychosocial problems among preschool children.

The study from Taiwan by $\mathrm{Lu}$ et al. [6] examined the risk factors for fractures among children with Tourette syndrome (TS) and comprised an equally impressive study cohort: 1258 children diagnosed with TS and 12,580 matched controls without TS. It is well established that TS is associated with self-injury, but there has been a lack of population-based studies examining associations between TS and other types of injuries. The Taiwanese study showed that, after adjusting for several covariates, the risk of fractures in the TS cohort was elevated by about $30 \%$. The increased risk was most apparent in skull, neck 
and spine fractures and more strongly associated with TS in children over 12 years of age. A novel finding, to be confirmed in future studies, was that antipsychotics reduced the fracture risk among TS patients. The authors eloquently addressed the limitations of their study and their findings are relevant for injury prevention and psychoeducation for children with TS and their families.

Let's put these two exciting studies into the wider context of the global development of CAP research. In order to address the ever-increasing global burden faced by CAMH, we need collaborative research from both western and nonwestern countries. There is a strong need for greater understanding of CAP, including the disease burden, and this will require comparative epidemiological studies across many countries. One major limitation in achieving this to date has been the difficulty in establishing and maintaining a global network of clinicians and researchers that focus on addressing CAP challenges. One such network is the Eurasian Child Mental Health Study group (EACMHS) [7], which was established in 2016 and brings together mental health researchers and clinicians involved in cross-cultural, multisite research projects on child and adolescent wellbeing and mental health in several Asian and European countries. The first project that EACMHS is investigating is the prevalence of mental health problems, perceived school safety and bullying and it is examining the associations between risky behaviors and well-being, mental health and helpseeking in this challenging context. The data collection was finalized in February 2017 and includes about 30,000 participants aged 13 to 16 years from 15 countries. It will be very interesting to see the group's findings in due course.

As Bob Dylan once famously sung "The times they are a changiń". Child and adolescent psychiatric research is taking steps towards being truly global and including research groups outside the western world will have a huge impact on our field. Establishing global collaborative networks of researchers to address the considerable challenges faced by today's young people is vital.

Acknowledgement We would like to acknowledge the contribution of the members of the EACMHS including: Samir Kumar Praharaj
(Kasturba Medical College, India), Liping Li (Shantou University, China), Tjhin Wiguna (University of Indonesia, Indonesia), Anat Brunstein-klomek (IDC,Israel), Hitoshi Kaneko (Nagoya University, Japan), Helena Slobodskaya (Novosibirsk State University, Russia), Zahra Zamani (Shahid Beheshti University of Medical Sciences, Iran), Sigita Lesinskienè (Vilnius University, Lithuania), Gerasimos Kolaitis (University of Athens,Greece), Sturla Fossum (UiT,Norway), Norbert Skokauskas (Norwegian University of Science and technology, Norway), Jarna Lindroos (University of Turku, Finland), Ong Say How (Institute of Mental Health, Singapore), Linh Vu (Children Hospital, Hanoi Vietnam), Olga Osokina (Donetsk National Medical University,Ukraine) and Chanvit Pornnoppadol (Mahidol University, Thailand).

\section{References}

1. Whiteford HA, Degenhardt L, Rehm J, Baxter AJ, Ferrari AJ, Erskine HE et al (2013) Global burden of disease attributable to mental and substance use disorders: findings from the Global Burden of Disease Study 2010. Lancet 382:1575-1586

2. Costello EJ, Mustillo S, Keller G, Angold A (2004) Prevalence of psychiatric disorders in childhood and adolescence. In: Levin BL, Petrila J, Hennessy KD (eds) Mental health services: a public health perspective, 2nd edn. Oxford University Press, Oxford, pp 111-128

3. UN (2009) World population prospects: the 2008 revision. Available from http://www.un.org/esa/population/publications/wpp2008/wpp2008_highlights.pdf (Accessed Jan 2017). Accessed 24 Nov 2016

4. Mokdad AH, Forouzanfar MH, Daoud F, Mokdad AA, El Bcheraoui C, Moradi-Lakeh M et al (2016) Global burden of diseases, injuries, and risk factors for young people's health during 1990 2013: a systematic analysis for the Global Burden of Disease Study 2013. Lancet 387(10036):2383-2401

5. Wu X, Tao S, Rutayisire E, Chen Y, Huang K, Tao F (2017) The relationship between screen time, nighttime sleep duration, and behavioural problems in preschool children in China. Eur Child Adolesc Psychiatry. doi:10.1007/s00787-016-0912-8

6. Lu YY, Wang MY, Wei IH, Lin CC, Huang CC (2017) Tourette syndrome increases risk of bone fractures: a populationbased cohort study. Eur Child Adolesc Psychiatry. doi:10.1007/ s00787-016-0916-4

7. Chudal R (2016) Eurasia Child Mental Health Group Report. World Child and Adolescent Psychiatry. Issue 11 (10-11) December 2016. Available from https://www.aacap.org/App Themes/AACAP/docs/homepage/headlines/2017/WORLD_ CAP_Dec_2016.pdf. Accessed 8 Mar 2017 